\title{
Papers
}

\section{Examination of environmental beliefs and its impact on the influence of price, quality and demographic characteristics with respect to green purchase intention}

Received (in revised form): 13th March, 2007

\section{Clare D'Souza}

is a senior lecturer in the Business School at La Trobe University, Australia. Her key research interests include environmental marketing with special interest in social implications of corporate marketing decisions, and green products marketing communication. She can be contacted at cdsouza@ latrobe.edu.au

\section{Mehdi Taghian}

is a senior lecturer in International Marketing at Deakin University, Australia. His key research interests include environmental marketing, marketing audit and marketing strategy.

\section{Rajiv Khosla}

is an associate professor at the School of Business, La Trobe University, Australia. He has a multidisciplinary background in management, engineering and computer science. His key research interests include management information systems and cognitive models. He can be contacted at R.Khosla@latrobe.edu.au

\section{Keywords environment, consumer behaviour, green marketing}

Abstract Research indicates that the environment has had a definite impact on consumer behaviour whereby suggesting to target consumers according to their environmental beliefs. This study investigated the consumers' green purchase behaviour using price and quality attributes as contributors to the formation of purchase intention. It attempts to construct a model that may facilitate the better understanding of green consumers' market segments through the use of an intelligent soft computing model. The model is designed to incorporate knowledge, beliefs, demographic profiles and situational variables. This potentially provides a more direct method for companies to gauge consumers' intention to purchase green products. The results showed strong preference for companies to place higher priority on reducing pollution than on increasing profitability. It highlighted different clusters that demonstrate various levels of the strength of intention to purchase and market segment profiles.

Journal of Targeting, Measurement and Analysis for Marketing (2007) 15, 69-78. doi:10.1057/palgrave.jt.5750039

\section{INTRODUCTION}

The publicity given to the Kyoto protocol in Australia and the increasing greenhouse

Correspondence: Mehdi Taghian, Deakin Business School, Deakin University, Toorak Campus, 336 Glenferrie Road, Malvern Victoria 3144, Australia. Tel: 6139244 5053;

Fax: 61392445533

E-mail: mehdi.taghian@deakin.edu.au emissions reported in the mass media in recent times have emphasised that businesses require being more socially responsible. Manufacturers, motivated by the achievement of their organisational objectives, have initiated development and modification of some production processes in order to support environmental protection. With increased 
stakeholder demands, especially consumer pressure on protection of the environment, businesses have moved beyond simply addressing environmental regulatory issues and are introducing alternatives such as new products that are classified as green. ${ }^{1}$ Some business have developed packaging that is environmentally friendly or supporting cause-related promotions.

However, at present, businesses find it difficult to predict consumers' reaction towards green products with a degree of accuracy that is necessary to enable the development of new targeting and segmenting strategies. This presumably has contributed to the failure in green products development. The key issue lies in an understanding of green consumers and their characteristics.

Other issues that have increasingly led to the slow development of green products are strategic issues initiated by businesses, such as charging higher prices or constraints on quality measures for green products.

In this paper, we attempt to investigate and detail the design of a soft computing model using Kohonen's LVQ technique for predicting the consumers' purchase intention of green products. It suggests characterising green market segments using price and quality dimensions as bases for segmentation. By evaluating the profile of a green consumer, it is anticipated that a more practical understanding of progress towards green measures can be achieved by businesses.

\section{BACKGROUND RELATED TO ENVIRONMENTAL MARKETING RESEARCH}

There are a few ways by which a green product can be distinguished. Green products have to represent a significant achievement in reducing environmental impact; they may also have to incorporate strategies of recycling, recycled content, reduced packaging or using less toxic materials. $^{2}$

While there has been much talk about corporations turning towards sustainability and becoming environmentally friendly (Wasik, ${ }^{3}$ Bennett, ${ }^{4}$ Drumwright, ${ }^{5}$ Sheth and Parvartiyar ${ }^{6}$ ) many efforts have been made to define green consumers (Benett, ${ }^{7}$ Brown and Wahlers, ${ }^{8}$ Dagnoli ${ }^{9}$ ), with conflicting results. It has been suggested that consumers' green preferences may be better appreciated within the context of a holistic social interaction rather than in isolation (Peattie, ${ }^{10}$ p. 164). Thus, as Wind ${ }^{11}$ suggested instead of turning the green market into a set of identified generalisations, it would be more practical for the development of business strategies to investigate consumer modifications in purchase behaviour, in terms of product attributes such as price and quality.

There is evidence to suggest that consumers are price and quality sensitive when it comes to 'buying green'. ${ }^{12}$ Other researchers have attempted to identify green consumer's profiles with an intention to characterise green market segments using demographic variables (McKenzie, ${ }^{13}$ Roberts, ${ }^{14}$ Titterington et al., ${ }^{15}$ Brown and Wahlers, ${ }^{16}$ ) and they have been able to categorise them as being young, well-educated and affluent urban dwellers (Arbuthnot, ${ }^{17}$ Weigel $^{18}$ ). In comparison, Jolibert and Baumgartner ${ }^{19}$ found that although green consumers were younger and more highly educated, their green attitude was not income related. Other studies have indicated that environmental concern and behaviour were stronger for persons above 50 years of age (Gallup and Newport, ${ }^{20}$ Kohut and Shriver, ${ }^{21}$ Lansana, ${ }^{22}$ Vining and $\left.\mathrm{Ebreo}^{23}\right)$. At the same time, price sensitivity appears to be a factor that is more directly related to income or the established purchase pattern associated with older age groups. Price and quality variations combined may provide the consumer a chance of exercising trade-offs for a purchase decision. Some research clearly indicates that committed environmentalists were more likely to purchase products on their environmental credentials, with price being less of a factor in the purchase decision. ${ }^{24}$ In order to explain the impact of price and quality on consumers' green demand, this study attempts to combine those factors with the demographic profiles of consumers forming distinct clusters or market segments, along with their environmental beliefs. 


\section{DESIGNING PREDICTORS OF ENVIRONMENTAL PROFILE ANALYSIS}

Unlike other research that examined various social-psychological, behavioural, recycling or attitudinal factors, this research focuses its stand on environmental beliefs, values and knowledge about environmentalism. Reid has concluded that the environment has had a definite impact on consumer behaviour and has identified four segments whereby suggesting to target consumers according to environmental beliefs. ${ }^{25}$

Basically knowledge advocates beliefs and values. Environmental knowledge can be defined 'as a general knowledge of facts, concepts, and relationships concerning the natural environment and its major ecosystems' (Fryxell and Lo, ${ }^{26}$ p. 45). Thus, in simple terms, environmental knowledge involves what people know about the environment and the beliefs that they hold about key environmental aspects or impacts.

The theory reveals that consumers who are knowledgeable about the problems of the environment will be motivated towards green purchase. ${ }^{10}$ While researchers (Hines et al., ${ }^{27}$ Schann and $\mathrm{Holzer}^{28}$ ) found that it was not just knowledge of environmental issues that had an impact on consumer behaviour but also the action strategies that are available to respond to environmental issues.

Although there are problems in measuring environmental knowledge, knowledge forms the basis of environmental awareness and beliefs. Amyx et al. ${ }^{29}$ found that subjective knowledge was preferred over objective knowledge. Their research indicated that higher levels of subjective knowledge were associated with higher incomes but there was no relationship between higher levels of subjective knowledge and individuals' age, education, gender or home ownership.

Thogerson and Olander ${ }^{30}$ suggest that sustainable consumption is influenced by individuals' value-priorities. There is also verification from research conducted by Karp ${ }^{31}$ that green consumers were more likely to hold altruistic values. While $\mathrm{Chan}^{32}$ found that those who shopped regularly for 'green' products and spent more on green products, in comparison to other products, were more likely to score highly on measure of biospherism, which related to a 'man-nature' orientation. Roberts ${ }^{33}$ indicated that those who scored highly on his 'Ecologically Conscious Consumer Scale' were more likely to believe in 'limits to growth', a 'spaceship earth' and an 'equality with nature'. This provides further substantiation that those more heavily engaged in eco-centric and biospheric values and beliefs are more likely to be green consumers. Thus, having recognised consumer environmental beliefs and values, we would like to identify how these consumers who hold strong beliefs react to price and quality of green products and whether there would be a trade-off?

In order to provide a more meaningful rationalisation, our next concern is to look at demographic profiles. The key issue is that the same purchase can be made based on different motives, and influenced by a combination of several demographic profiles, knowledge, attitudes, past experiences and values. ${ }^{10}$

With regards to demographic profiles, there has been no significant link found between demographic segmentation and green purchase. ${ }^{34}$ This could be due to the notion that different groups of people relate to different parts of the environmental agenda. ${ }^{10}$ There have been contradictory results of younger and older age groups concerns about environmental issues. ${ }^{10}$ There is, however, a belief that environmental concern is directly related to a consumer's level of education. ${ }^{35}$ Based on four surveys, Hines et al. ${ }^{36}$ found no relationship with gender.

\section{METHOD}

\section{Data collection}

A survey research was designed and implemented to collect empirical data enabling the grouping of respondents with respect to their price and product quality attributes of green products. The research instrument used in this study was 
structured based on prior qualitative research and the literature review. The instrument was pretested and modified to include variables contributing to the customers' formation of the overall perception about environmentally safe products. All measurements were subjective assessments by the respondents using a sevenpoint Likert-type scale. ${ }^{37}$ The sample was randomly drawn from the residential telephone directory of Victoria (Australia) including both metropolitan and regional areas. The questionnaires were administered over a weekend using Quantum Research data collection services. The respondents were the main buyers of food from supermarkets irrespective of gender. A total of 155 questionnaires were completed and were used for data analysis.

The sample selection method using a random telephone dialling was expected to provide a representative sample of the supermarket shoppers' population. No nonresponse rate has been reported as the automatic telephone dialling would select the next call to replace the unsuccessful call.

The selected sample's main characteristics were female (79 per cent), 35-54 years old (49 per cent), married (65 per cent) with children (47 per cent), secondary school educated (60 per cent) and employed (50 per cent). The data were analysed using both descriptive measures and cluster analysis to identify and validate the items contributing to each component in the model developed. The resulting instrument included items to measure customers' product perception of quality and price by using Kohonen's LVQ behaviour prediction agent, which is discussed below.

\section{Kohonen's LVQ technique}

In this section, we describe aspects related to Kohonen's LVQ behaviour prediction agent, used for learning and predicting the fuzzy behavioural categories. Kohonen's self-organising maps are characterised by a drive to model the selforganising and adaptive learning features of the brain. The learning algorithm organises the nodes in the two-dimensional grid into local neighbourhoods or clusters that act as feature classifiers on the input data. The advantage of developing neighbourhoods is that vectors that are close spatially to the training values will still be classified correctly even though the network has not seen them before, thus providing for generalisation.

Since Kohonen's network is an unsupervised self-organising learning paradigm, Kohonen also introduced a supervised learning technique called Learning Vector Quantisation (LVQ). LVQ method is very useful because it amounts to a method for fine-tuning a trained feature map to optimise its performance in altering circumstances. The basic feature of LVQ method is that we can add new training vectors at typical situations to improve the performance of individual neighbourhoods within the map. This can be achieved by selecting training vector $(x)$ with known classification, and presenting them to the network to examine cases of misclassification. Again a best match comparison is performed at each node and the winner is noted $\left(n_{w}\right)$ (Beale and Jackson, ${ }^{38}$ p. 122).

The LVQ prediction model used in this work is based on the need to develop an incremental learning model of green purchase based on price and quality.

In order to develop a predictive model, we need to determine green consumer cluster groups related to purchase intention. These cluster groups then will become the dependent variable to be predicted by the LVQ technique. In the rest of this section, we first describe the identification of purchase intention cluster groups and then follow it up with the design and implementation of the prediction model.

\section{LEARNING GREEN CONSUMER CLUSTER GROUPS}

The purchase intention of green consumers is broken down into two dimensions or attributes, namely, price and quality of the green products. The price and quality dimensions are assumed to be influenced by beliefs or values and customer characteristic variables. In all, 20 variables or data points (under the above categories) were used to cluster green consumer groups as follows: 


\section{Beliefs/values on environment:}

I believe there are a lot of exaggerations about companies taking environmental risks nowadays. I believe the government is doing all that is possible to safeguard the environment.

I believe that we should not slow down industry progress because of concern for the environment. I believe environmental safety is the responsibility of the government, not individual citizens. I believe that government legislation adequately regulates environmental protection.

I believe a well-known brand is always a safe product to buy.

I believe that the quality of environmentally safe products is not as good as other products.

I believe that the price of environmentally safe products is usually more expensive than other products.

I believe Australian companies are generally doing a good job in helping to protect the environment.

I believe companies should place higher priority on reducing pollution than on increasing their own profitability.
I believe companies should place higher priority on reducing pollution than on increasing profitability even if jobs are at risk.

\section{Situational factors (price and quality) on green products}

I prefer to purchase an environmentally safe product even if it is somewhat more expensive. I prefer to purchase an environmentally safe product even if it is somewhat lower in quality.

In the rest of the paper, we will describe the design of a soft computing model using Kohonen's LVQ technique for predicting the purchase intention of green consumers of green products.

Figure 1 shows a sample of the consumer behavioural patterns used as data set for learning the fuzzy behavioural categories/clusters towards price and quality. Initially ten clusters were obtained for price and 17 clusters obtained for quality. It was found that consumers were more densely clustered on the quality dimension of the product than on price, indicating stronger

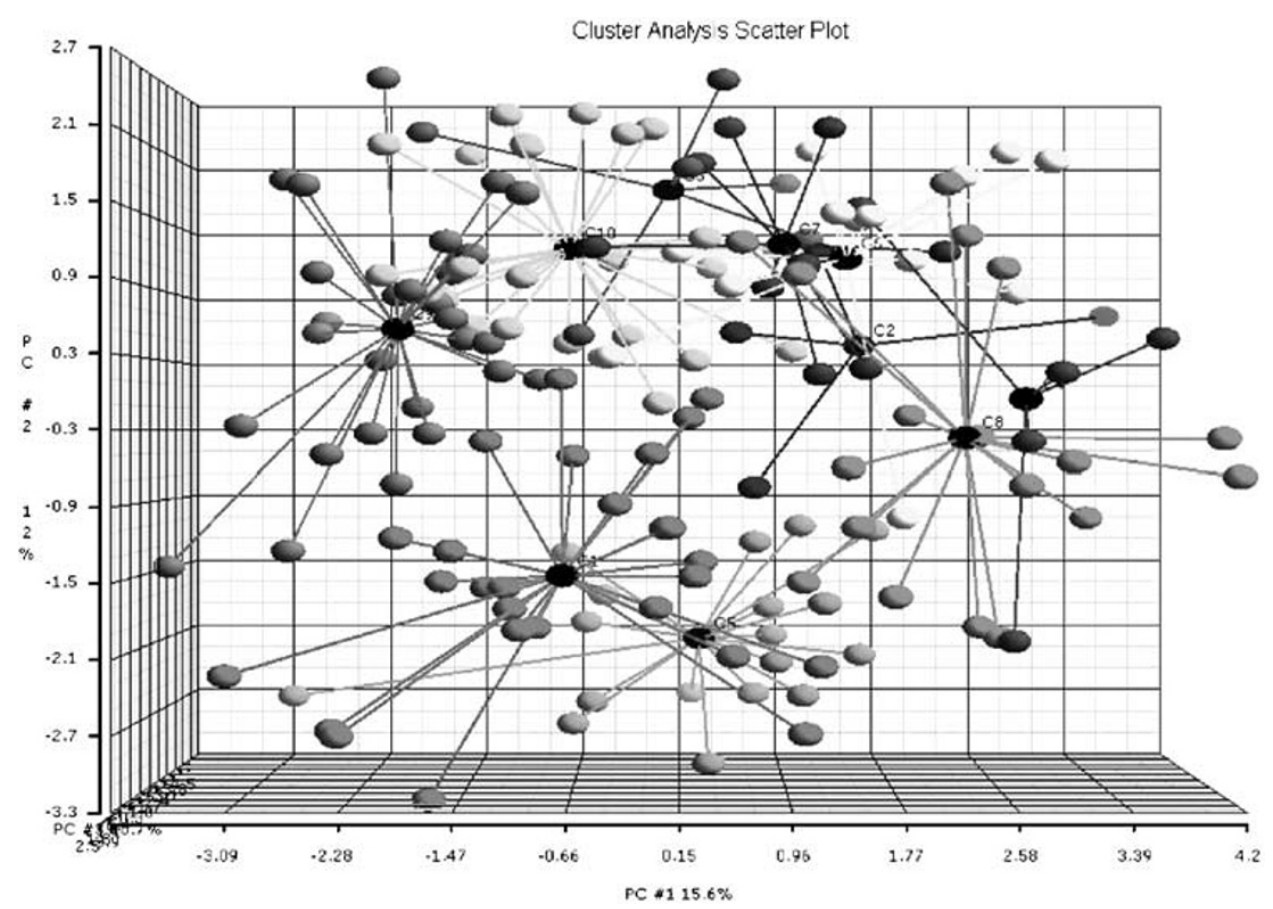

Figure 1: Price cluster analysis 
resistance to lower quality and relatively more relaxed in terms of higher prices.

Figure 2 shows the clusters based on cognitive, affective, customer characteristics and price/quality variables. Thus, Figure 1 shows 11 price/quality-based clusters. Of these ten price- based clusters are distinct green customer groups whose purchase intentions are influenced by different beliefs, attitudes and demographic characteristics.

Eight of the 11 clusters shown in Figure 2 are plotted on a two-dimensional price and quality

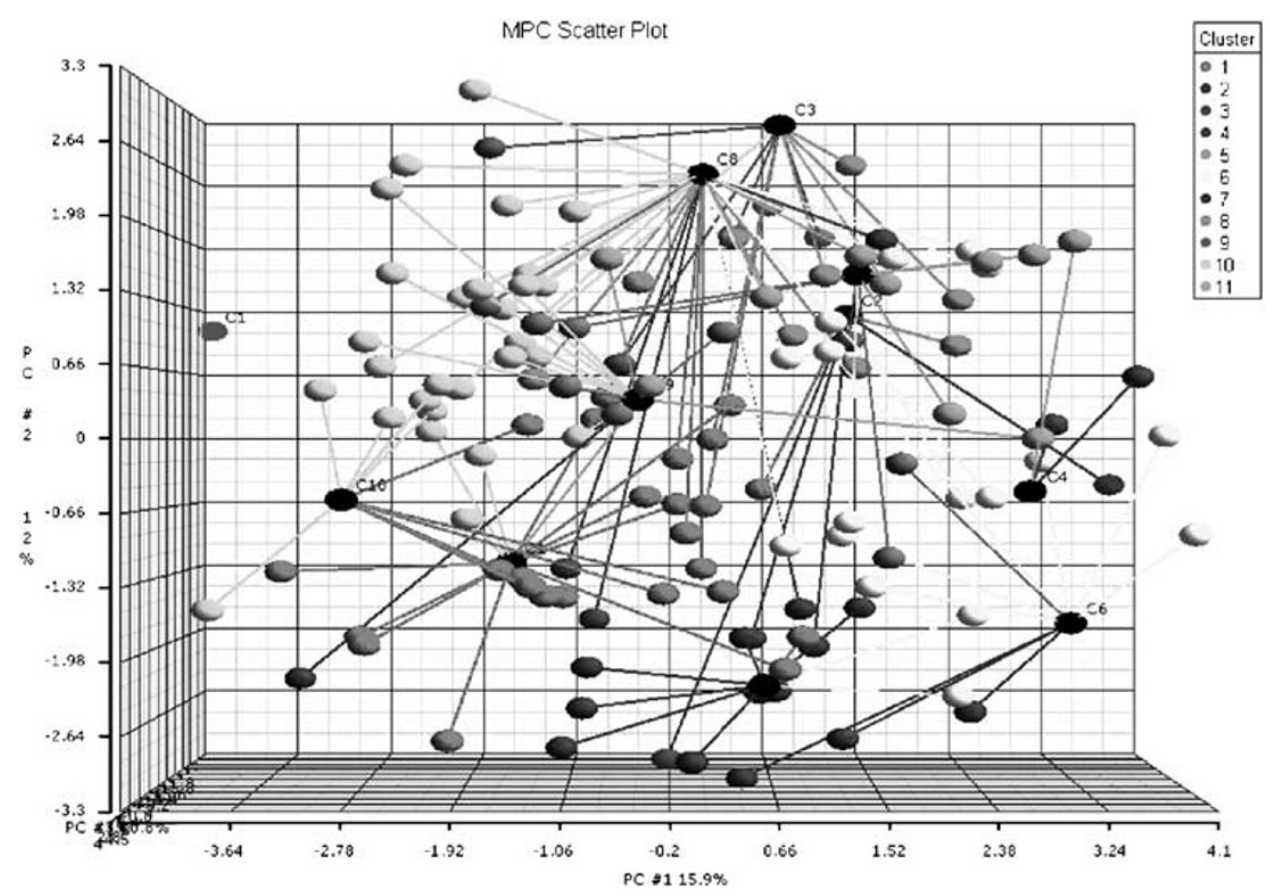

Figure 2: Price/quality cluster analysis

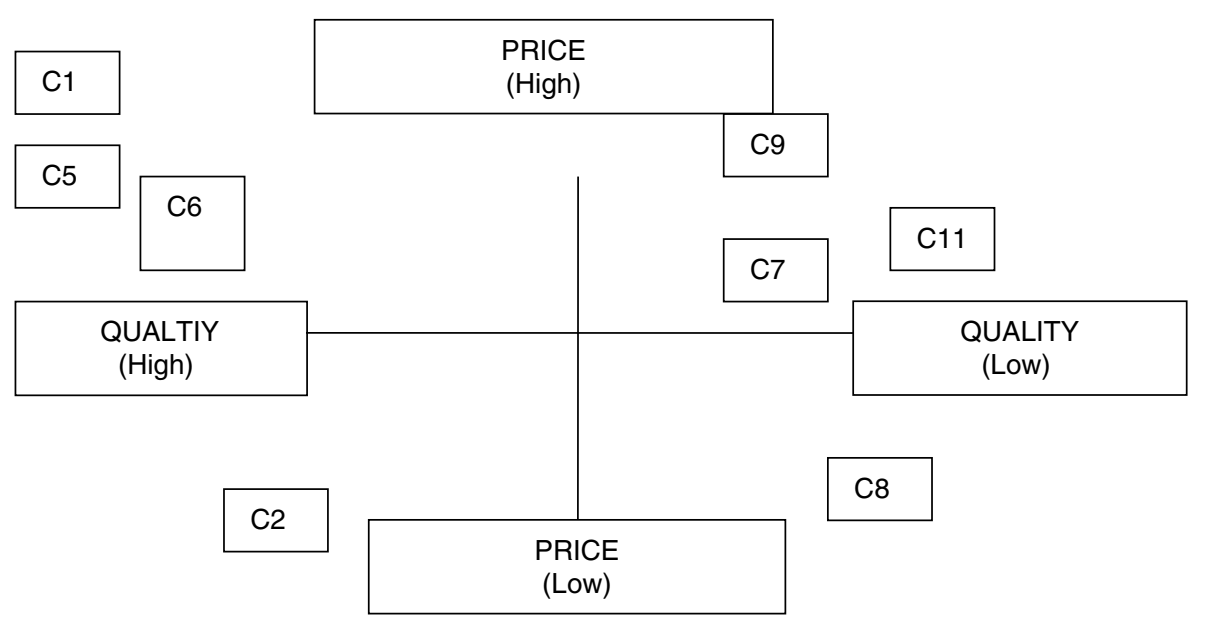

Figure 3: Purchase intention clusters and two-dimensional price-quality model 
Table 1: LVQ based predictive model

\begin{tabular}{|c|c|c|c|c|c|c|}
\hline Categories & \# per class & \# Correct & \# Error & $\%$ Correct & $\%$ Error & Std error \\
\hline 1 & 26 & 26 & 0 & 100.0 & 0.0 & 0.0 \\
\hline 5 & 11 & 10 & 1 & 90.9 & 9.19 & 8.7 \\
\hline 6 & 17 & 16 & 1 & 94.1 & 5.9 & 7.1 \\
\hline 7 & 19 & 18 & 1 & 94.7 & 5.3 & 5.1 \\
\hline 8 & 11 & 11 & 0 & 100.0 & 0.0 & 0.0 \\
\hline 9 & 3 & 1 & 2 & 33.3 & 66.7 & 10.5 \\
\hline 11 & 1 & 1 & 0 & 100.0 & 0.0 & 4.9 \\
\hline Total & 88 & 83 & 5 & 94.3 & 5.7 & 2.4 \\
\hline
\end{tabular}

model in Figure 3. A sample data set used for developing the LVQ-based predictive model is shown in Table 1 . As can be seen, we have used only eight out of the 11 purchase intention categories (based on 11 price and quality clusters identified in the preceding section). The three cluster categories, 3, 4 and 10 are not included in Table 1 and in Figure 3 forms the outliers of the two-dimensional price and quality model.

In order to establish the prediction accuracy of the Kohonen's LVQ model, we have used the cross-validation technique for estimating generalisation error based on 're-sampling'. ${ }^{39}$ It shows a total accuracy of 94.32 per cent.

\section{QUADRANT 1 - PRICE (HIGH) AND QUALITY (HIGH)}

Quadrant 1 included respondents who formed clusters that would prefer to purchase environmentally safe product if it was somewhat more expensive and were of somewhat higher quality.

\section{Cluster one}

\section{Consumers in cluster one:}

- Strongly agreed on their belief that companies should place higher priorities on reducing pollution than on increasing their own profitability.

- Majority of the consumers belonged to an older age group; they had no children and were retired.

\section{Cluster five}

Consumers in cluster five:

- Strongly agreed that there are exaggerations about companies taking environmental risks.

- Consumers disagreed on government legislation adequately regulates environmental protection.

- Consumers strongly agreed that companies should place higher priority on reducing pollution than on increasing their own profitability.

- Most of the consumers were in full time employment and were employed as white collared workers.

\section{Cluster six}

\section{Consumers in cluster six:}

- Strongly agreed that we should not slow down industry progress because of concern for the environment.

- Strongly agreed that well-known brand is always a safe product to buy.

- Strongly agreed that the prices of environmentally safe products are usually more expensive than other products.

- Strongly agreed that companies should place higher priority on reducing pollution than on increasing their own profitability.

- Married or in de facto relationship, year 10 and under and had no occupation.

While there is a variation in the demographic profiles, in these three clusters all consumers strongly agreed that companies should place higher priority on reducing pollution than on increasing their own profitability. 


\section{QUADRANT II - PRICE (HIGH) AND QUALITY (LOW)}

Quadrant II included consumers who formed clusters that would prefer to purchase environmentally safe products if they had somewhat higher prices and were somewhat of lower quality in comparison to the alternative products.

\section{Cluster seven}

Consumers in cluster seven:

- Strongly disagreed that the government is doing all that is possible to safeguard the environment.

- Consumers agreed that companies should place higher priority on reducing pollution than on increasing their own profitability.

- Single, living alone, completed Higher Secondary, retired.

\section{Cluster nine}

Consumers in cluster nine:

- Strongly agreed that we should not slow down industry progress because of concerns for the environment.

- Strongly agreed that companies should place higher priority on reducing pollution than on increasing their own profitability.

- No children.

\section{Cluster eleven}

\section{Consumers in cluster eleven:}

- Disagreed that the quality of environmentally safe products are not as good as other products.

- Agreed that Australian companies are generally doing a good job in helping to protect the environment.

- Strongly agreed that companies should place higher priority on reducing pollution than on increasing their own profitability.

- Married de facto - and no occupation.
In this quadrant as well, while there is a variation in the demographic profiles, in these three clusters all consumers, strongly agreed that companies should place higher priority on reducing pollution than on increasing their own profitability.

\section{QUADRANT III PRICE LOW/ QUALITY LOW}

Quadrant III includes consumers who formed clusters that would prefer to purchase environmentally safe product if it was somewhat lower in price and were somewhat lower in quality in comparison to the alternative products.

\section{Cluster eight}

\section{Consumers in cluster eight:}

- Neither agreed nor disagreed that the government legislation adequately regulates environmental protection.

- Married/de facto.

\section{QUADRANT IV PRICE (LOW) AND QUALITY (HIGH)}

Quadrant IV included consumers who formed clusters that would prefer to purchase environmentally safe product if it was somewhat lower in price and was of higher quality in comparison to the alternative products.

\section{Cluster two}

\section{Consumers in cluster two:}

- Strongly agreed that we should not slow down industry progress because of concern for the environment.

- Consumers in this group had completed higher secondary education and had no occupation.

The larger number of clusters fell in quadrant I Price High/Quality High and quadrant II Price High/Quality Low. 
In both these quadrants, the research indicated that all clusters showed strong preference for companies to place higher priority on reducing pollution than on increasing their own profitability.

\section{MANAGERIAL IMPLICATIONS}

Peattie $^{10}$ indicated that if the majority of consumers were offered credible green products with similar prices and technical performance to conventional products, consumers would discriminate in favour of the green products. Thus, for marketers of green products, the challenge lies in how to identify environmental beliefs and values consumers hold about green products in order to target them. For those consumers who do not currently purchase green products, the question is whether and how they can be motivated to become potential green consumers.

The present study has found evidence to suggest that there appears to be a fundamental expectation existing on the part of the customer about all products to be green and friendly to the environment. From the cluster analysis, it can be explained that consumer attitude appears to be that they are less likely to compromise on product quality than on somewhat higher prices of green products. Thus with respect to business strategy, arguably, this may mean two things: (1) manufacturers may produce higher quality green products and use the premium pricing strategy commensurate with the higher costs of production or (2) they may compete in the marketplace offering comparable product quality standards at the competitive price categories in the market. The second option may require investment in refining production processes and employing technology more effectively to create lower cost-based production processes.

It can be seen that buying intent for green products is also associated with customer's personal characteristics. Consumer demographics play a role in cluster analysis. In essence, to target these markets effectively, managers may benefit from segmenting the market based on consumer's green demographic profile. Further research could investigate this issue more fully.

For those companies that intend to use the green product offering as a competitive advantage, it appears to be fundamental to segment their markets based on the three combined dimensions of price/quality/demographic characteristics and be able to quantify each segment for their attractiveness and purchase readiness.

Keller ${ }^{40}$ has identified ten top traits for the world's strongest brands. In order to build up a strong green brand, there appears to be a need for consideration of a pricing strategy in line with consumers' perception and strength of attitude toward value and specifically about green values. Therefore, for environmental marketers pricing may involve a three-way balance between price, eco-performance and primary performance to create a green value strategy. ${ }^{10}$

A fundamental issue is whether green consumers can be targeted. This study suggests that those consumers whose beliefs extend positively towards the environment, potentially, demonstrate a relatively consistent response format and commonality of intention to purchase. Therefore, this target market may be attractive and could, potentially, be served using a well-structured and formulated environmental marketing strategy and consistent implementation.

\section{CONCLUSIONS}

In summary, the understanding of the green products perception formation, potentially, has a number of applications. The analysis provides the motivations for management (1) to build a strong competitive advantage for the product, in terms of quality and price, (2) to develop and project a profile of green consumer based on demographics and (3) to meet customers' expectations by genuinely being as well as effectively being recognised by consumers as being demonstrably socially responsible. This strategy may offer the potential benefits of improvement in market share and assist to achieve sustainable longer term profitability. 


\section{References}

1 Greenhouse Challenge (2005) 'The challenge', Department of the Environment and Heritage, Australian Green House Office (issue, May).

2 Wasik, J. (1996) 'Green Marketing and Management: A Global Perspective', Blackwell Publishers Ltd., United Kingdom.

3 Wasik, J. (1996) 'Green Marketing and Management: A Global Perspective', Blackwell Publishers Ltd., United Kingdom.

4 Bennett, S. (1992) 'Green commitment: Fading out?' Progressive Grocer, Vol. 71, No. 12, pp. 4-7.

5 Drumwright, M. (1994) 'Socially responsible organizational buying: Environmental concern as a noneconomic buying criterion', Journal of Marketing, Vol. 58(July), pp. 1-19.

6 Sheth, J. and Parvartiyar, A. (1995) 'Ecological imperatives and the role of marketing', in Polonsky, M. and Mintu-Wilmsatt, A. (eds) 'Environmental Marketing: Strategies, Practice, Theory and Research', Haworth Press, New York, pp. 3-20.

7 Bennett, S. (1992) 'Green commitment: Fading out?' Progressive Grocer, Vol. 71, No. 12, pp. 4-7.

8 Brown, J. and Wahlers, R. (1998) 'The environmentally concerned consumer: An exploratory study', Journal of Marketing Theory and Practice, Vol. 6, No. 2, pp. 39-47.

9 Dagnoli, J. (1991) 'Consciously green', Advertising Age, Vol. 14(September), p. 41.

10 Peattie, K. (1995) 'Environmental Marketing Management: Meeting the Green Challenge', Pitman Publishing, London.

11 Wind, Y. (1978) 'Issues and advances in segmentation research', Journal of Marketing Research, Vol. 15, No. 3, pp. 317-338.

12 Mandese, J. (1991) 'New study finds green confusion', Advertising Age, Vol. 62, No. 45, pp. 1-56.

13 McKenzie, D. (1991) 'The rise of the green consumer', Consumer Policy Review, Vol. 1, No. 2, pp. 68-75.

14 Roberts, J. (1996) 'Green consumers in the 1990s: Profile and implications for advertising', Journal of Business Research, Vol. 36, No. 2, pp. 217-231.

15 Titterington, A., Davies, C. and Cochrane, A. (1996) 'Forty shades of green: A classification of green consumerism in Northern Ireland', Journal of Euro-Marketing, Vol. 5, No. 3, pp. 43-55.

16 Brown, J. and Wahlers, R. (1998) 'The environmentally concerned consumer: An exploratory study', Journal of Marketing Theory and Practice, Vol. 6, No. 2, pp. 39-47.

17 Arbuthnot, J. (1977) 'The roles of attitudinal and personality variables in the prediction of environmental behavior and knowledge', Environment and Behavior, Vol. 9, No.2, pp. 217-232.

18 Weigel, R.H. (1977) 'Ideological and demographic correlates of proecological behavior', The Journal of Social Psychology, Vol. 103, pp. 39-47.

19 Jolibert, A. and Baumgartner, G. (1981) 'Toward a definition of the consumerist segment in France', Journal of Consumer Research, Vol. 8, No. 1, June, pp. 114-117.

20 Gallup, G. and Newport, F. (1990) 'Americans strongly in tune with the purpose of Earth Day 1990', Gallup Poll Monthly, Vol. 295(April), pp. 5-21.

21 Kohut, A. and Shriver, J. (1989) 'Environment regaining a foothold on the national agenda', Gallup Report, Vol. 285, pp. 2-12.

22 Lansana, F. M. (1992) 'Distinguishing potential recyclers from non-recyclers: A basis for developing recycling strategies', The Journal of Environmental Education, Vol. 23, pp. 16-23.
23 Vining, J. and Ebreo, A. (1990) 'What makes a recycler? A comparison of recyclers and non-recyclers', Environment and Behavior, Vol. 22, pp. 55-73.

24 Gilg, A., Barr, S. and Ford, N. (2005) 'Green consumption or sustainable lifestyles? Identifying the sustainable consumer', Futures, Vol. 37, No. 6, pp. 481-506.

25 Schlossberg, H. (1992) 'Latest trend: Targeting consumers according to environmental beliefs', Marketing News, Vol. 26, No. 1, p. 5 .

26 Fryxell, G. and Lo, C. (2003) 'The influence of environmental knowledge and values on managerial behaviours on behalf of the environment: An empirical examination of managers in China', Journal of Business Ethics, Vol. 46, No. 1, pp. 45-50.

27 Hines, J. M., Hungerford, H. R. and Tomera, A. N. (1987) 'Analysis and synthesis of research on responsible environmental behavior: A meta-analysis', The Journal of Environmental Education, Vol. 18, No. 2, pp. 1-29.

28 Schann, J. and Holzer, E. (1990) 'Studies of individual environmental concern: The role of knowledge, gender and background variables', Environment and behaviour, Vol. 22, No. 6, pp. 767-786.

29 Amyx, D. A., DeJong, P. F., Lin, S., Chakraborty, G. and Wiener, J. L. (1994) 'Influencers of purchase intentions for ecologically safe products: An exploratory study', in Park, C.W. and Smith, D.C. (eds) ' Marketing Theory and Applications Proceedings of the 1994 AMA Winter Educators' Conference, pp. 341-347.

30 Thogerson, J. and Olander, F. (2002) 'Human values and the emergence of a sustainable consumption pattern: A panel study', Journal of Economic Psychology, Vol. 23, No. 1, pp. 605-630.

31 Karp, D. (1996) 'Values and their effect on pro-environmental behavior', Environment and Behavior, Vol. 28, pp. 111-133.

32 Chan, R. (2001) 'Determinants of Chinese consumers' green purchase behavior', Psychology and Marketing, Vol. 18, pp. 389-413.

33 Roberts, J. (1996) 'Green consumers in the 1990's: Profile and implications for advertising', Journal of Business Research, Vol. 36, pp. 217-231.

34 Kinnear, T. and Taylor, J. (1973) 'The effect of ecological concern on brand perceptions', Journal of Marketing Research, Vol. 10(May), pp. 191-197.

35 Balderjahn, I. (1988) 'Personality variables and environmental attitudes as predictors of ecologically responsible consumption patterns', Journal of Business Research, Vol. 17, pp. 51-56.

36 Hines, J. M., Hungerford, H. R. and Tomera, A. N. (1987) 'Analysis and synthesis of research on responsible environmental behavior: A meta-analysis', The Journal of Environmental Education, Vol. 18, No. 2, pp. 1-29.

37 Wren, B. S. (1997) 'The market orientation construct: Measurement and scaling issues', Journal of Marketing Theory and Practice, Vol. 5, No. 3, pp. 31-54.

38 Beale, R. and Jackson, T. (1990) 'Neural Computing: An Introduction', Adam Hilger, Bristol.

39 Efron, B. and Tibshirani, R. (1997) 'Improvements on crossvalidation: The $0.632+$ Bootstrap method', Journal of the American Statistics Association, Vol. 92, pp. 548-568.

40 Keller, K (2001) 'The Brand Report Card in Harvard Business Review on Marketing', Harvard Business School Publishing, Boston. 